\title{
EXPERIENCE OF A LIFETIME: STUDY ABROAD, TRAUMA, AND INSTITUTIONAL BETRAYAL
}

\author{
by \\ NAOMI M. WRIGHT
}

\begin{abstract}
A THESIS
Presented to the Department of Psychology and the Robert D. Clark Honors College in partial fulfillment of the requirements for the degree of Bachelor of Arts
\end{abstract}

June 2015 


\section{An Abstract of the Thesis of}

Naomi M. Wright for the degree of Bachelor of Arts

in the Department of Psychology to be taken June, 2015.

Title: Experience of a Lifetime: Study Abroad, Trauma, And Institutional Betrayal

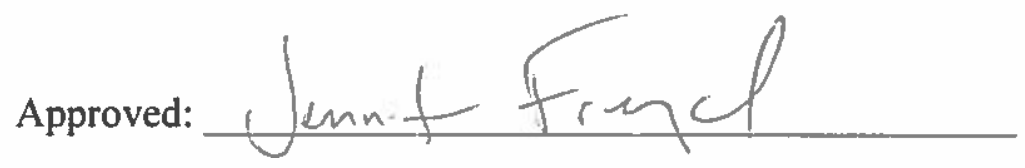

Jennifer J. Freyd, Ph.D.

Although the number of U.S. undergraduates studying abroad during college continues to increase, emerging research suggests these students are at risk for experiencing trauma (Kimble, Flack, \& Burbridge, 2013; Flack et. al., 2014). The current study is the first to expand the investigation of study abroad risks to include a range of possible traumas and to examine the unique effects of institutional betrayal (i.e., an institution's failure to adequately prevent trauma or support victims) in the study-abroad setting. In a sample of university students who had studied abroad, many respondents $(45.44 \%, n=79)$ reported personally experiencing or witnessing at least one traumatic experience while abroad. Of these students, more than a third $(35.44 \%, n$ =28) also reported experiencing at least one form of related institutional betrayal. When controlling for trauma history, the experience of institutional betrayal uniquely predicted posttraumatic outcomes for witnessing and experiencing several types of study abroad trauma. This study revealed that students experience a broader range of traumatic events during study abroad than previous research has documented. Additionally, this study extends prior research by underscoring the importance of understanding institutional impact before, during, and after a student studies abroad. 


\section{Acknowledgements}

I would like to thank those people who lent me their support and energy during the nearly two years of conducting this project. To my committee, Dr. Jennifer Freyd, Dr. Carly Smith, and Dr. Joseph Fracchia: I cannot express enough thanks for your continued support and encouragement. Jennifer, when I sat down in your class nearly two years ago, I did not know I was about to discover one of my great passions. Thank you for showing me it is possible to be an activist, a scholar, and a compassionate human being. Carly, thank you for being an ever-conscientious and intentional mentor. Professor Fracchia, thank you for giving me new lenses to see the world's flaws, and the hope that we will find a way to change them.

I thank the Robert D. Clark Honors College for funding this endeavor with the CHC Thesis Scholarship. The support and participation of the University of Oregon Office of Study Abroad was integral to the recruitment of participants in this study. I thank the UO Office of Research Compliance and the Committee for the Protection of Human Subjects for ensuring our research followed best ethical practices, particularly the tireless work of Psychology Department IRB liaison, Bill Schumacher.

My completion of this project could not have been accomplished without the support of my Psychology honors program peers, especially Megan, Alex, and Alia. I thank my friend Maddie for countless cups of tea and commiseration. The Dynamics Lab members not only provided me much needed feedback and encouragement, but also served as amazing role models. Thanks as well to my sister, Aedin, and my mother, Mary. Finally, to my caring, loving, and supportive partner, Scott: my deepest gratitude. You never failed to supply snacks or kind words when I needed them most. 


\section{Table of Contents}

Introduction $\quad 1$

Background 3

$\begin{array}{ll}\text { Purpose } & 11\end{array}$

Method 12

$\begin{array}{ll}\text { Participants } & 12\end{array}$

Procedure 13

$\begin{array}{ll}\text { Measures } & 15\end{array}$

Data Preparation and Analysis 19

$\begin{array}{ll}\text { Results } & 22\end{array}$

Discussion 30

Limitations $\quad 38$

$\begin{array}{ll}\text { Conclusion } & 40\end{array}$

Bibliography $\quad 41$

Appendix A: Recruitment Letter 45

Appendix B: Snowballing Recruitment Message $\quad 46$

Appendix C: Consent Script $\quad 47$

Appendix D: Debriefing Statement 49

Appendix E: BBTS 50

Appendix F: LEC-5 51

Appendix G: IBQ-IS 53

Appendix H: TSC-40 55

Appendix I: WAQ 56 


\section{List of Figures}

Figure 1. Peace Corps Crime Victimization Rates 6

Figure 2. Two-Dimensional Model of Trauma 8

Figure 3. Frequency of Language Fluency 13

Figure 4. Perpetrator Identity for Personally Experienced Interpersonal Traumatic $\begin{array}{ll}\text { Events } & 23\end{array}$

Figure 5. Perpetrator Identity for Witnessed Interpersonal Traumatic Events 24

Figure 6. Trauma Symptoms by Timing of Trauma 25

Figure 7. Types of Institutions Cited for Betrayal by Frequency of Endorsement 35 


\section{List of Tables}

Table 1. Types of Institutional Betrayal by Frequency of Experience 27

Table 2. Institutional Betrayal as a Predictor of Study Abroad Trauma Distress 28 


\section{Introduction}

Mallory ${ }^{1}$, a young woman studying abroad in Central America, was sexually assaulted while on an outing at the beach with friends (Redden, 2014). ${ }^{2}$ Beyond the upheaval inherent to rape, in the proceeding days and weeks, the actions of the study abroad program's executive director further exacerbated Mallory’s ordeal. Just four days after the assault the administrator attempted to coerce Mallory into reporting the incident to police and signing a legal waiver of liability without a lawyer present. As Mallory describes, the same administrator "repeatedly made [her] feel uncomfortable and singled out.” Confusingly, the administrator also tried to praise and placate Mallory both in public and private, including offering a "bribe:” an upgrade to luxury accommodations (Smyth, 2014). Further, the administrator telephoned Mallory's homestay house, even approached Mallory without warning on the street in another attempt to have her sign more paperwork. The administrator may have believed her actions to be supportive, and she was undoubtedly balancing the confusing, possibly conflicting, obligations to protect institution, law, and student. However, the administrator’s actions left Mallory feeling it was “impossible to begin healing” until there was evidence of the program improving measures for student safety, and changing the response to incidents students experience.

When Mallory wrote to the administrator to ask to discontinue contact, the administrator complied. Unfortunately, there were still further negative outcomes. The two professors who were most helpful to Mallory following the assault—who took her

1 The student's true name was not released to the public.

2 The perpetrator has not been identified; it is not clear whether the assailant was a fellow student or a member of the host country. 
into their home, obtained emergency contraceptives, and offered continued supportwere fired for acting "in violation of... protocol” by contacting Mallory and helping her obtain medical care without administrative knowledge. Mallory and her family expressed "eternal[] grat[itude] to these two [professors] who stepped in as parents when [her own parents] were physically unable to.” In addition to firing the professors, the program lost its affiliation with Mallory's U.S. college, which resulted in the cancellation of many students’ planned study abroad trips. Mallory “constantly fight[s] the urge to [take] the blame for what happened to [her] professors and [future students in the program]" (Smyth, 2014).

Mallory labels the mishandled response from her study abroad program as a "revictimization" that was "intrusive" during the time she should have been allowed to begin the process of recovery. Indeed, in an open letter to her college and the study abroad program, Mallory stated that changes to the emergency protocol of the school and study abroad program, would be necessary "in order to make this situation right, to allow my healing process to truly begin, and quite honestly, to sleep soundly at night” (Smyth, 2014).

Research from the field of psychology suggests not only that exposure to traumatic events while studying abroad is common, but also that the way in which institutions respond has the potential to exacerbate a student's negative reaction to that event. Given the paucity of research about study-abroad programs, the present study aims to explore both the prevalence of students' exposure to traumatic events during study abroad, and the effects of the institutional culture and actions on the after-effects of traumatic events experienced during study abroad. 


\section{Background}

The modern university student is heavily encouraged to spend a semester or more studying in a country outside the United States, but little research has examined students' experiences during study abroad. Over the past two decades, the number of U.S. American students studying abroad ${ }^{3}$ has more than tripled, and continues to increase, such that more than 283,000 students studied abroad in the 2011-2012 school year (Institute of International Education [IIE], 2013). Because of substantial government and private support for the idea of studying abroad, this trend is likely to continue. As the U.S. Assistant Secretary of State for Education and Cultural Affairs stated in November 2013, "We encourage U.S. schools to continue to [...] do more to make study abroad a reality for all of their students” (IIE, 2013).

Despite the increase in study abroad enrollment, there has been little examination of the risks students face while studying abroad, the efficacy of riskprevention education, or institutions' support of students in the event of traumatic event. Colleges, universities, and independent study abroad programs focus on the personal, professional, and cultural benefits when recruiting students to study abroad, but often minimize potential risk factors and challenges (Bolen, 2001). Program brochures, posters, websites, and other advertising materials present a package of "youth, fun, and exotic locations,” and often project the message that students will be positively affected and benefit from studying abroad (Bolen, 2001; Bishop, 2013).

3 For the purposes of this investigation, "study abroad" refers to all programs where students receive college-level credit through international participation, including direct enrollment in a local university, field-based studying with a group from the US, professional internships, or a combination of these programs. 
Though limited, previous findings suggest that students studying abroad face an increased risk for traumatic experience. Recent research examined female undergraduates’ exposure to attempted and completed sexual assault while studying abroad, relative to on-campus assaults (Kimble, Flack, \& Burbridge, 2013; Flack, Kimble, Campbell, Hopper, Petercă, \& Heller, 2014). In both studies, participants reported high rates of exposure to unwanted sexual experiences (including nonconsensual touching, attempted or completed assault) while abroad ranging from 18.8\% (Flack et al., 2014) to 38.1\% (Kimble et al., 2013). These rates equal or exceed those observed for female students on domestic U.S. campuses. This is particularly alarming given that most study-abroad programs are shorter than the reference periods used in most domestic studies of campus sexual assault ${ }^{4}$.

Given the paucity of research, individual risk factors for sexual assault during study abroad are unclear. Kimble et al. (2013) found a geographical correlation, with higher assault rates occurring in non-English speaking countries. Neither Kimble et al. (2013), nor Flack et al., 2014) found that students’ self-reported language fluency predicted sexual assault victimization. The identity of perpetrators differed between these two studies. The majority of perpetrators in Kimble et al.'s (2013) study were nonstudent, local residents of the abroad country. Conversely, Flack et al., (2014) found the majority of perpetrators to be fellow university students participating in study abroad, from either the victim's home university or another U.S. university. Despite the lack of agreement between these studies, these findings suggest students that may face elevated risks based on individual differences.

4 Studies of campus sexual assault on college campuses use reference periods ranging from one year to entire college career. 
Further research suggests that, although students perceive a risk of psychological distress associated with study abroad, they feel confident in their ability to handle any risk they encounter while traveling (Hartjes, Baumann, \& Henriques, 2009). Beyond this, the existing body of research lacks inquiries into study-abroad students' experience of other forms of traumatic events. Similar experiences, like that of Peace Corps volunteers, provide additional understanding of the risk for trauma exposure during study abroad. Aggregates of Peace Corps volunteers’ crime victimization ${ }^{5}$ indicate $22.1 \%$ of Corps members experience at least one crime annually (Peace Corps, 2014; see Figure 1).

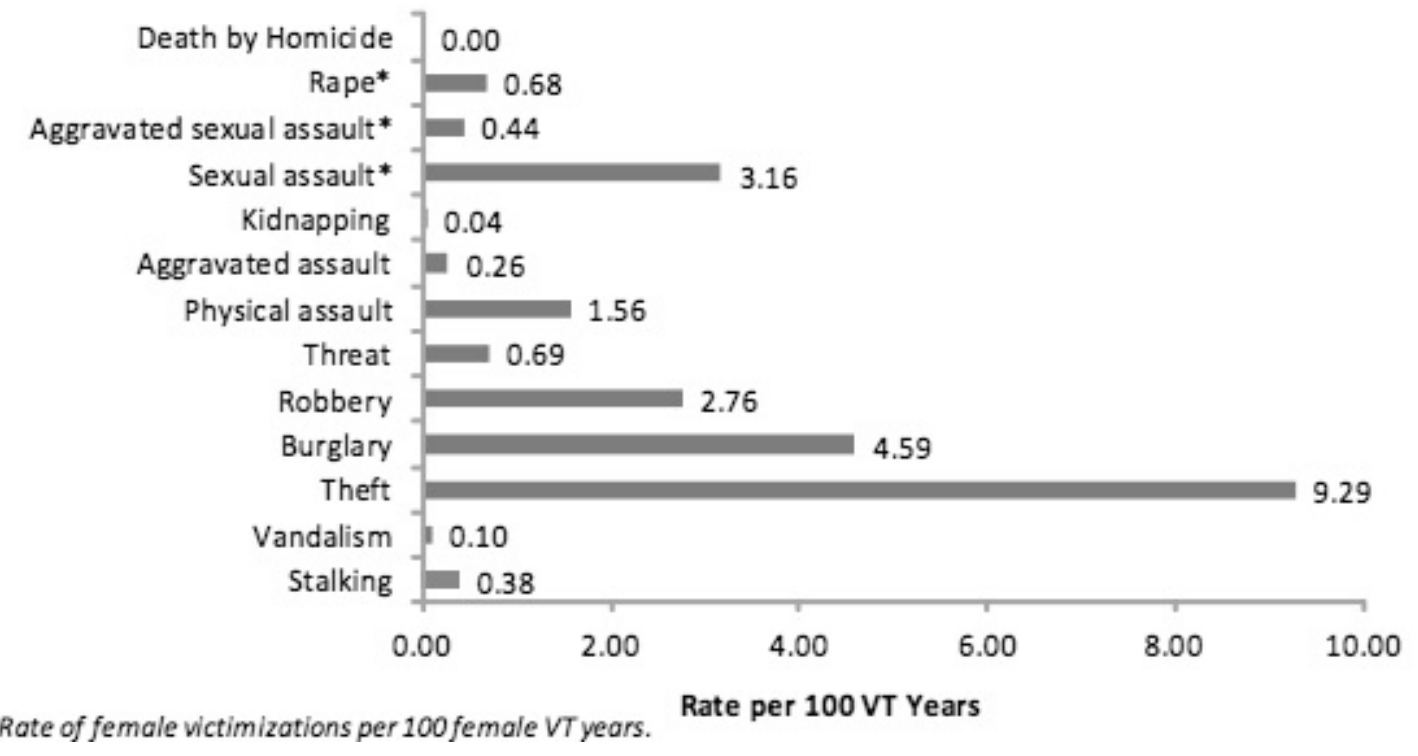

5 Crime victimization includes: death by homicide, rape, aggravated sexual assault, sexual assault, kidnapping, aggravated assault, physical assault, threat, robbery, burglary, theft, vandalism, stalking. 
Figure 1. Peace Corps Crime Victimization Rates

Bar graph depicting incidence rates of reported victimizations in the 2013 volunteer year for all Peace Corps volunteers (Peace Corps, 2014). Note: VT years

(volunteer/trainee years) are used rather than the population of volunteers in an effort to represent only the time during which a volunteer is "in the field," and therefore at risk.

These rates may be lower than the reality of volunteers' experience, because the report had access only to the crimes that volunteers formally reported to the Peace Corps. Safety tips and prevention materials for the broader population of U.S. Americans traveling internationally also indicate that traveling poses risk of exposure to a range of traumatic experiences. For example, the Centers for Disease Control and Prevention (2013) suggests that U.S. Americans abroad should be aware of increased risk for travel-related illness, injury, transportation accidents, physical or sexual assault, harassment, natural disaster, and witnessing others’ experience of such events.

Given the likelihood of students' exposure to traumatic experiences while studying abroad, the role of supporting institutions in responding to students must be examined. Though no national or international standard exists to regulate student safety or institution support, Bolen (2001) found that many students and their families expect their college or university to act in loco parentis ${ }^{6}$ during the student's time abroad. Because of the students' lack of knowledge in the international context, students necessarily rely (to varrying degrees) on university advisors and program staff for protection of their well being. In this sense, the relationship between the student abroad and their sponsor school parallels that of other dependent institutional relationships: the

6 In loco parentis: Latin, in place of the parent. 
employee and the organization that employs them, the church member and her Diocese, or the soldier and the Department of Defense. In all of these cases, the member places tremendous trust in their institution and expects support in the face of adversity (Freyd \& Birrell, 2013).

When an individual trusts or depends on an institution in this manner, there is potential for betrayal. Betrayal trauma theory (Freyd, 1994, 1996; Freyd et al., 2007) explains the unique consequences incidental to the experience of trauma within this type of close relationship. Though betrayal trauma theory was originally developed to understand abuse occurring in close relationships, it has been applied to institutions (e.g., Smith \& Freyd, 2013). The conventional belief is that an event must cause terror or fear (e.g., a natural disaster, combat exposure, or a violent mugging) to be traumatic. However, betrayal trauma theory asserts that trauma also contains another dimension, ranging in degree of social-betrayal (see Figure 2). 


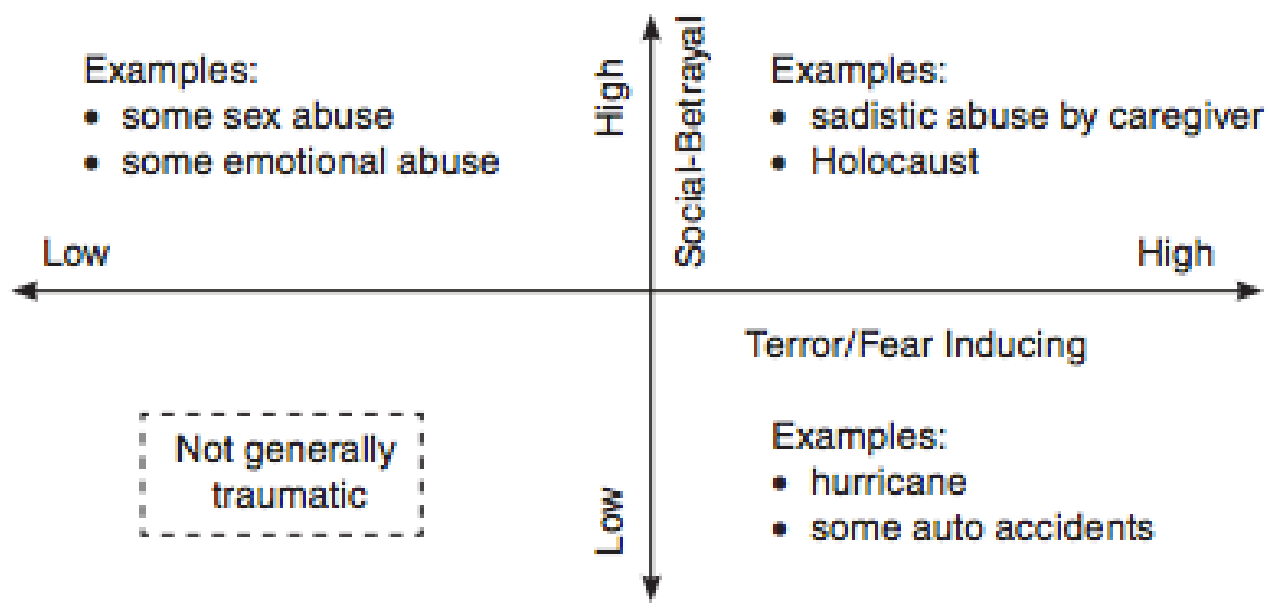

Figure 2. Two-Dimensional Model of Trauma

Graph depicting dimensions of trauma, including social betrayal. Copyright 1996 by Jennifer J. Freyd.

Moreover, extensive research suggests that "high-betrayal” traumas (those where the individual has a trusting or dependent relationship with the perpetrator) have unique posttraumatic outcomes. The most salient example is betrayal blindness, the phenomenon of conscious unawareness that occurs when a trusted or depended-upon other perpetrates abuse (Freyd, 1994, 1997). Such blindness can range from minor (as in the willingness to ignore signs a partner is unfaithful) to extreme (such as total memory absence for instances of physical or sexual abuse; Gobin \& Freyd, 2009). It may seem counterintuitive that one would create psychic mechanisms to ignore a source of danger, but individuals are often unable to (or perceive themselves to be unable to) leave the abusive situation (e.g., a child, or a partner with children and no income source). In these cases, on-going awareness of past abuse or present danger may be a source of stress and impair an individual's ability to engage in the types of behaviors that maintain the necessary relationship (e.g., seeking closeness; Freyd, 1996). 
The mechanism of betrayal blindness allows individuals to remain largely unconscious of the betrayal occurring, which facilitates the maintenance of the relationship that is necessary for survival. The mind does not wholly erase knowledge of the betrayal; rather it may partially compartmentalize the information or fully keep it from conscious awareness. Despite the mind blocking knowledge of the abuse from conscious awareness, the traumatic experience takes a toll. Often, these effects manifest indirectly through physical and psychological symptoms that occur without apparent cause (Beck, Elzevier, Pelger, Putter, \& Voorham-van der Zalm, 2009; Ross, 2005; Courtois, 1997; Briere \& Spinazzola, 2005; Kaehler \& Freyd, 2009; Trippany, Helm, \& Simpson, 2006). Because the individual cannot consciously connect the sequelae of betrayal traumas with a cause, betrayal has the potential to induce more complex and prolonged distress. Contrary to popular conceptions of posttraumatic stress disorder (PTSD) as a response only to violent or fear-inducing traumas, betrayal adds to the toxicity of experiencing trauma, particularly avoidance and numbing symptoms (Kelley, Weathers, Mason, \& Pruneau, 2012).

In the same way that these mechanisms occur between individuals, Smith and Freyd (2013) examined the unique application of betrayal trauma theory to trusting relationships between individuals and an institution. Specifically, they investigated the betrayal of female sexual assault victims by their college or university, what they term “institutional betrayal.” Those participants who reported experiencing institutional betrayal (e.g., an institution [college, fraternity, church, etc.] played a role in the traumatic event by creating an environment in which the event seemed more likely to occur, responding inadequately to the experience, if reported, suggesting the experience 
might affect the institution's reputation, etc.) displayed significantly more severe posttraumatic reactions than those who reported no experience of institutional betrayal (Smith \& Freyd, 2013). Although focused on women who were sexually assaulted, the study suggests the scope of institutional betrayal extends to populations that are more diverse and to the experience of a broader range of traumatic events.

The study-abroad setting is a unique context for institutional betrayal, in part because the role of the institution is so salient. While abroad, students may be more reliant on institutional representatives (e.g., support staff, teachers, host-family members, etc.) than they would be on a home campus. Individuals' reliance on institutions mirrors interdependence between individuals. This is a normal human tendency that stems from humans' fundamental interconnectedness as social beings (Mayseless \& Popper, 2007). When abroad, it can be more difficult to contact family or members of other supportive social structures. This lack of self-sufficiency, decreased access to other support, and an increased risk of traumatic experience makes studying abroad a unique and important context in which to examine institutional betrayal. For example, a study-abroad program or sponsor university could create an environment where the traumatic event seemed likely to occur, such as allowing students to use a shoddy bus until a car accident occurs, or continuing a partnership with a translator known to have had inappropriate sexual contact with a student. Thus, the existing body of research indicates that U.S. American students risk exposure to traumatic events by studying internationally, and individuals who trust and rely on an institution may be additionally traumatized by their institution's betrayal in response to the traumatic experience. 


\section{Purpose}

This study had two main objectives. First, this study involved a preliminary analysis of the effects of traumatic experiences for students studying abroad, including prevalence and potential individual risk factors. The present study predicted students would report exposure to potentially traumatic experiences at rates similar to or exceeding their peers who remained on a U.S. campus, based on national statistics.

Second, this study tested the hypothesis that, when compared with students whose study-abroad trauma did not involve institutional betrayal, students who were exposed to trauma while studying abroad in conjunction with institutional betrayal would exhibit more negative outcomes in two areas: indicators of psychological distress and indicators of assumptive views of the world. 


\section{Method}

\section{Participants}

The sample consisted of undergraduate students at a large, public university in the Pacific Northwest who had received college-level credit through international participation in study-abroad type programs, including direct enrollment in an abroad university, field-based study, professional internships, or a combination of these programs. This includes programs of any duration, through which students may have earned any number of credits. A total of 173 students, mostly female (77.5\%), Caucasian (79.3\%), and college-aged $(M=21.86, S D=3.65)$ successfully completed the survey. The sample was slightly more female than the population of students who had studied abroad (65\% female). Due to confidentiality constraints, the office of study abroad was unable to provide additional demographic information about the population of sudents who had studied abroad.

Participants provided additional information about their study abroad experience that might illuminate individual differences in traumatic experience or institutional betrayal susceptibility. Participants studied across seven different regions. ${ }^{7}$ Students most frequently spent one term abroad (i.e., 10-15 weeks; 41\%) or less than one term abroad (i.e., less than ten weeks; 39.3\%); less frequently, students spent more than a term but less than a full year abroad (13.9\%) or more than one full year (5.8\%). Most participants (75.7\%) had returned from studying abroad less than one year before completing the survey. The majority of participants described their level of fluency in

\footnotetext{
7 Regions of study (frequency in sample): Non-English-speaking Europe( 35.8\%), English-speaking Europe (18.5\%), Central and South America (14.5\%), Africa (11.6\%), Asia (13.9\%), North America (4\%), Australia (1.7\%).
} 
the language of their study abroad country as no proficiency (23.3\%) or elementary proficiency (23.3\%). For additional information about language proficiency, see Figure 3. Roughly half (50.9\%) the sample received funding or scholarships from a home college or university to study abroad.

\section{Language Fluency}

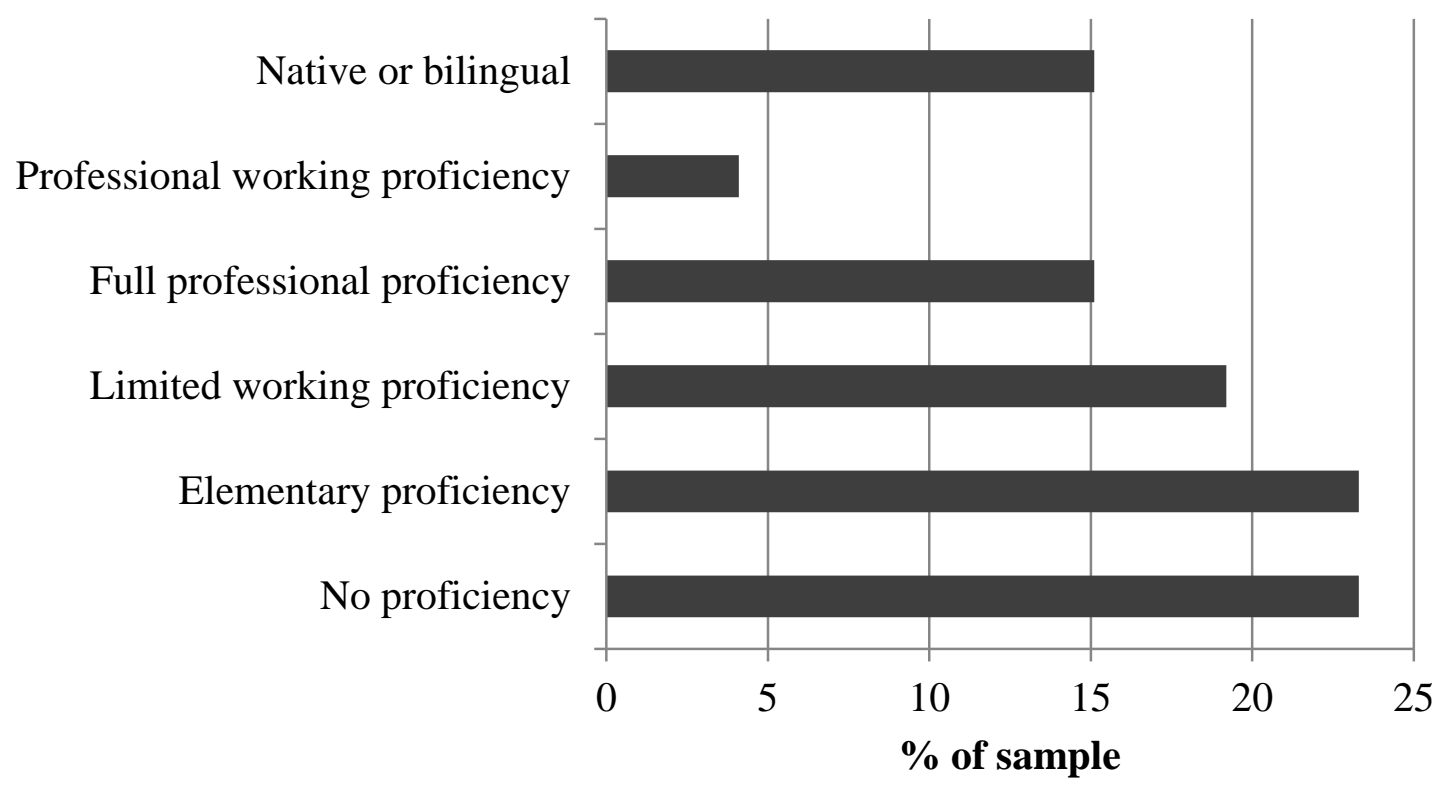

Figure 3. Language Fluency in the Sample

Bar graph depicting frequency of language fluency levels by percent of sample endorsing.

\section{Procedure}

Recruitment. Before beginning recruitment and data collection, the study received approval from the university's Office of Research Compliance. Participants were recruited through two channels. First, the university study-abroad office sent an email invitation to current students who studied abroad during their time at the university (See Appendix A for the full message). Second, after participating in the 
survey, subjects received a link to the survey that could distribute to other potential participants (See Appendix B). ${ }^{8}$

Participation was encouraged through a drawing, in which participants had the chance to receive one of forty $\$ 25.00$ gift certificates to the online retailer, Amazon.com. To distribute gift cards, participants reported contact information in an independent survey that followed the central questionnaire to protect anonymity.

Data collection. From the email, participants opened the survey link using a web browser on a personal computer, which took them to the online measure hosted with the web-based survey software Qualtrics. Before beginning the questionnaires, participants read a statement of consent (see Appendix C). To advance in the survey, participants were required to indicate they agreed to the terms of consent.

During the online survey, participants responded to a series of measures of trauma history, institutional betrayal, psychological distress symptoms, and worldview, as well as a brief demographics questionnaire. Participants indicated their response to items by marking a radial dial or typing a short-answer response. Participation took roughly thirty minutes.

After participation, students reviewed a debriefing statement that included information about registering for the compensation drawing, the study's purpose, and contact information for the study investigators and university and community counseling services, should questions from the survey cause adverse reactions (see Appendix D).

8 This is known as a "snowballing" method, where previous subjects recruit additional participants. 


\section{Measures}

The online survey consisted of questionnaires measuring (1) betrayal trauma at differing ages; (2) life stressors experienced outside and inside of the study abroad experience; (3) participants’ perception of institutional betrayal; (4) trauma-related problems; and (5) assumptions about the world.

Brief Betrayal Trauma Survey. Betrayal trauma history was measured using the Brief Betrayal Trauma Survey (BBTS; Goldberg \& Freyd, 2006; see Appendix E). It is a self-report measure of major traumatic events, originally consisting of 12 items that respondents may have experienced before age 12 , between ages $12-17$, and after age 18 . For the purposes of this study, the measure was modified in two ways. First, participants were asked only about traumatic events they had directly experienced. Second, the time periods have been modified to "before age 18," "after age 18 not while studying abroad,” and "after age 18 while studying abroad.”

The items are classified based on three levels of betrayal: low, medium, or high. Low-betrayal traumas are non-interpersonal (e.g., transportation accident) while medium- and high-betrayal traumas are interpersonal. Medium- and high-betrayal traumas (e.g., being attacked) are distinguished by the closeness of the relationship with the perpetrator. Medium-betrayal traumas are interpersonal in nature, but the perpetrator is not close to the participant (e.g., “you were deliberately attacked severely by someone with whom you were not close [italics added]). High-betrayal traumas involve a perpetrator who has a close relationship with the participant (e.g., you were made to have some form of sexual contact by someone with whom you were very close). The BBTS has been demonstrated to have good construct validity, meaning it is an accurate 
test of traumatic events (DePrince \& Freyd, 2001). It has also been shown to have good test-retest reliability, which means respondents receive similar scores if they repeat the measure (Goldberg \& Freyd, 2006).

Life Events Checklist for DSM-5. Traumatic experiences were measured using two versions of the Life Events Checklist for DSM-5 (LEC-5), modified to focus participant responses to two areas of their life history: the time outside study abroad and during study abroad (Weathers, Blake, Schnurr, Kaloupek, Marx, \& Keane, 2013; see Appendix F). This is a self-report measure consisting of 16 stressful and potentially traumatic life events (e.g., serious accident at work or school, home, or during recreational activity), with the option for respondents to write in an additional event they feel was not captured in the first 16 items. For each item, respondents have the option to select multiple options, including "happened to me," "witnessed it," "not sure,” or “doesn't apply to me.”

For the present study, one item was modified from "exposure to toxic substance, for example, dangerous chemicals, radiation" to "ingestion of so much alcohol or other substance that loss of consciousness or loss of control over actions resulted.” This change stemmed from the conjecture that students are not likely to be exposed to toxic chemicals, but might have a parallel “exposure” related to alcohol or other substances. Using selection logic, participants who endorsed an interpersonal traumatic event were shown a follow-up question asking about the identity of the perpetrator. Participants were asked whether the person who perpetrated the event was: a) A person from your home country that you knew; b) A person from your home country that you did not know; c) A person from your home country that you did not know; d) A host-country 
member you did not know; or e) Other, with a write-in box for participants to elaborate on the "Other" perpetrator.

The LEC-5 has been demonstrated to be a good measure of exposure to traumatic events, and has convergent validity with measures of trauma-related psychopathology (e.g., posttraumatic symptomology). The test-retest reliability of the LEC-5 proved stable over time (subscale kappas ranging from .37-.84; Weathers et. al., 2013).

Institutional Betrayal Questionnaire - International Study. An augmented version of the Institution Betrayal Questionnaire (IBQ; Smith \& Freyd, 2013) was used to evaluate institutional betrayal. The IBQ was originally developed to measure institutional betrayal in the context of sexual assault on a college campus. The measure consists of 12 items that describe possible ways in which an institution might have played a role in the traumatic event or experience (for full measure, see Appendix G). The original IBQ was modified for this study to tailor it to the experience of studying abroad in three ways: 1) two items were added that assessed institutional betrayal unique to study abroad, ${ }^{9}$ 2) the examples following items were tailored to study abroad experiences (e.g., Creating an environment in which this experience seemed more likely to occur [e.g., “That was just a cultural experience.”]), and 3) follow -up questions to indirectly measure respondents’ institutional loyalty or closeness (e.g., “Would you recommend that a friend participate in the same study abroad program you participated in?”) were also added. Using the display logic in the survey-hosting software, the questionnaire was constructed such that the IBQ was displayed only to participants who 
previously indicated that they experienced or witnessed a traumatic event while studying abroad.

Trauma Symptoms Checklist - 40. Psychological symptoms related to traumatic experience were assessed using the Trauma Symptom Checklist-40 (TSC-40) to measure participants' experience of six subscales of challenges related to psychological trauma: Anxiety, Depression, Dissociation, Sexual Abuse Trauma Index, Sexual Problems, and Sleep Disturbances (Elliott \& Briere, 1992). The measure consists of 40 items describing distress found to be associated with traumatic experiences.

Respondents indicated how often they experienced each symptom in the previous two months using a four-point scale of frequency, from 0 (“never”) to 3 (“often). A sample item is, "How often have you experienced the following in the last two months? Restless sleep,” (for full measure, see Appendix H). In the current study, the TSC-40 proved a reliable measure of post-traumatic symptoms $(\alpha=.93)$. Research suggests this scale has high internal consistency, meaning there are significant correlations between different items on the same test. All items were summed to create a total score, with higher scores indicating more severe trauma symptoms.

World Assumptions Questionnaire. Based on Assumptive World Theory (JanoffBulman, 1992), the World Assumptions Questionnaire (WAQ) quantifies the ways in which trauma survivors’ fundamental assumptions about the world are shattered following exposure to traumatic events. The WAQ comprises 22 questions divided into four subscales: Controllability of Events, Comprehensibility and Predictability of People, Trustworthiness and Goodness of People, and Safety and Vulnerability (Kaler, 2009; see Appendix I). The WAQ was recently developed and has not been 
implemented widely, but it has been demonstrated to be a reliable and valid measure of the assumptive world. In the present study, the WAQ was a reliable predictor of world assumptions ( $\alpha=.81)$. To create a composite score, all items from the WAQ were averaged to yield a score between zero and four, with higher scores indicating a more negatively assumptive worldview.

\section{Data Preparation and Analysis}

All analyses in this study were conducted using SPSS. Missing responses from items assessing demographic and measures of trauma exposure (e.g., LEC-5) were left missing. Scores on the TSC were positively skewed (skewness $=1.55, S E=0.18$ ), indicating that lower levels of posttraumatic outcomes were reported most frequently within the present sample.

The LEC-5 could be used as a continuous variable (i.e., summing the scores to represent total traumatic experiences) or as a categorical variable (i.e., no traumatic experiences vs. any traumatic experiences). Given the small sample size in the present study, using the LEC-5 as a categorical predictor allows group differences to emerge more clearly. Therefore, analyses of between-group differences were tested using SPSS's general linear model (GLM), which is conducive to testing of multiple categorical variables.

The first test analyzed the relative effects of the timing of traumatic experiences (i.e., outside of study abroad experiences vs. during study abroad) on posttraumatic symptoms individually. Because traumatic experiences outside of study abroad accounted for a significant amount of variance in trauma symptomology, they were controlled for in the analysis of the association between institutional betrayal, and 
posttraumatic symptoms. For this test, a GLM analysis was used because it allows for the examination of the unique contribution of individual variables while simultaneously controlling for other variables in a model. For example, non-study-abroad trauma was included as a covariate in each model testing the effects of institutional betrayal on trauma symptoms in order to determine the unique predictive value of institutional betrayal trauma above and beyond individuals’ experience of additional lifetime trauma.

Controlling for non-study-abroad trauma as a covariate, the first model examined the effect of any study-abroad trauma as a predictor of trauma symptoms. As the LEC-5 lends itself to classifying different traumatic experiences (e.g., witnessing or experiencing, non-interpersonal, interpersonal, etc.), the associations between the six subtypes of traumatic events on the LEC-5 and institutional betrayal were examined individually using separate GLM analyses also with non-study-abroad trauma as a covariate.

The BBTS was used to compute a measure of participants' experience of childhood high-betrayal trauma. High-betrayal items (those involving an interpersonal traumatic experience with a close other) from the "before age 18” time period were summed. Participants who had endorsed experiencing at least one high-betrayal item before age 18 were said to have experienced "any HBT"; those who had endorsed no high-betrayal items were said to have experienced "no HBT”. The interaction between HBT and IBQ was tested using a univariate GLM.

In reporting the results of analyses, both $p$-values ${ }^{10}$ and generalized eta squared $\left(\eta_{G}^{2}\right)$ effect sizes ${ }^{11}$ have been reported. Increasingly, the social sciences are relying on

\footnotetext{
${ }^{10}$ Probability or "p-values" indicate the likelihood the observed outcome is erroneously true.
} 
this practice and it is of particular importance with the present study because the small sample size may limit the utility of relying on significance testing alone. Generalized eta square measures provide indices of effect that are consistent with Cohen's (1988) guidelines for defining the magnitude of the effect (Olejnik \& Algina, 2003). Thus, the Cohen's d small ( $\eta^{2}{ }_{G}=.01 ; 1 \%$ of variance explained $)$, medium $\left(\eta^{2}{ }_{G}=.10 ; 10 \%\right.$ of variance explained), and large $\left(\eta^{2}{ }_{G}=.25 ; 25 \%\right.$ of variance explained), categories will be used to estimate the strength of effects.

${ }^{11}$ Generalized eta squared effect sizes indicate the proportion of the variance in the dependent variable explained by the independent variable of interest. 


\section{Results}

A majority of respondents $(86.78 \%, n=151)$ reported personally experiencing or witnessing at least one traumatic event during their lifetime, outside of study abroad. Additionally, 45.44\% $(n=79)$ of the sample reported experiencing a traumatic event while studying abroad. Of the participants who reported exposure to a traumatic event while studying abroad, $28.6 \%$ reported personally experiencing one or more traumatic events, $26.2 \%$ reported witnessing one or more traumatic events, and $45.2 \%$ reported both personally experiencing and witnessing one or more traumatic events. The length of time students were abroad significantly predicted exposure to traumatic experiences, $F(1,172)=3.59, p=.015, \eta^{2}{ }_{G}=.06$, with students spending more time abroad experiencing a greater mean number of traumatic events. Additionally, language proficiency predicted trauma exposure. Those who self-reported with a language fluency of "no proficiency" were least likely to experience trauma, $F(1,166)=6.328, p$ $=.013, d=0.352$. Those with self-described near-native levels of fluency were most likely to experience a traumatic event, $F(1,166)=4.44, p=.037, d=0.664$. However, when controlling for duration of study abroad programs, language proficiency was no longer a significant predictor of likelihood of traumatic exposure.

For interpersonal events, participants were asked to report the identity of the perpetrator. For personally experienced traumatic events, the most frequently reported perpetrator identity (38\% of interpersonal events) was "A host country member that [the participant] did not know.” For witnessed traumatic events, the majority of participants chose not to report a perpetrator (59\% of witnessed events). For a more detailed depiction of perpetration see Figure 4 and Figure 5. 


\section{Perpetrator Identity for Personally Experienced Interpersonal Traumatic Events}

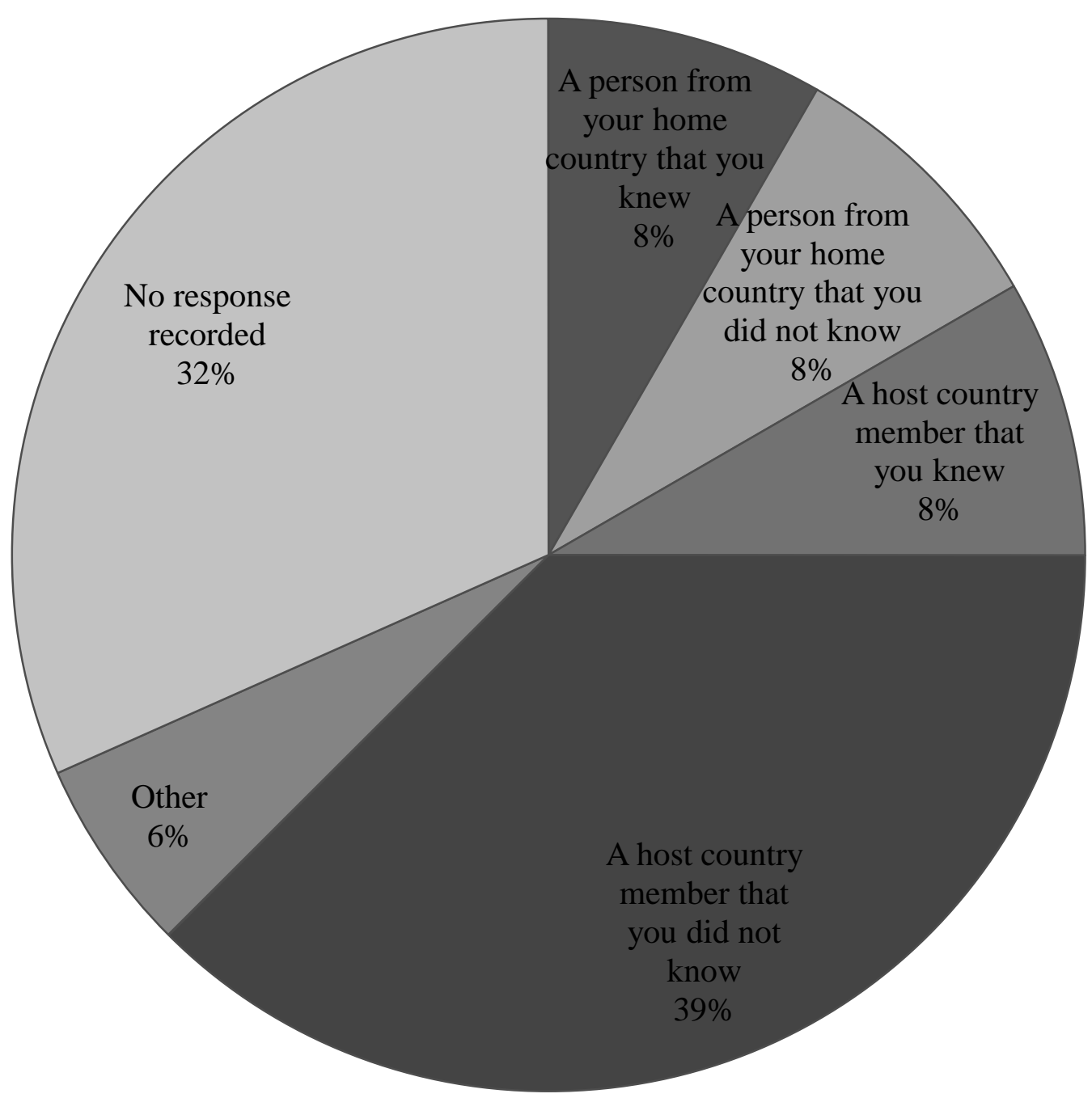

Figure 4. Perpetrator Identity for Personally Experienced Interpersonal Traumatic

Events

A pie chart depicting reported perpetrator identity for interpersonal traumatic events the participant had personally experienced. 


\section{Perpetrator Identity for Witnessed Interpersonal Traumatic Events}

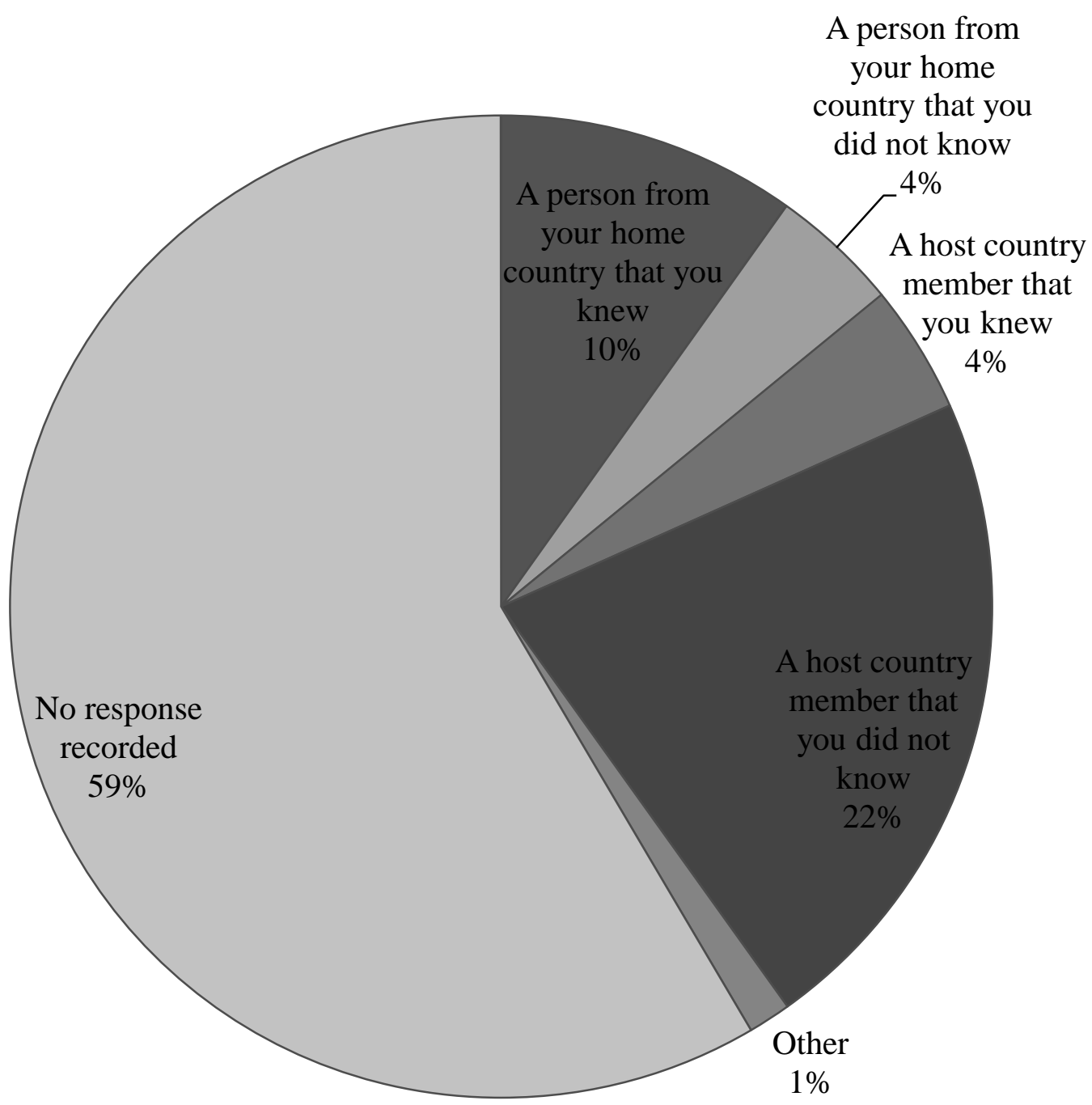

Figure 5. Perpetrator Identity for Witnessed Interpersonal Traumatic Events

A pie chart depicting reported perpetrator identity for interpersonal traumatic events the participant witnessed another person experiencing. 
Of respondents who had experienced a traumatic event while studying abroad, almost all (98.7\%) also reported experiencing a traumatic event at another point during their lifetime. A comparison of the proportion of participants who reported experiencing additional lifetime trauma for those who reported no study abroad trauma $(M=.77, S D=.42)$ and those who reported any study abroad trauma $(M=.99, S D=$ .11) revealed a significant difference in lifetime traumatic experiences between the two groups, $t(172)=-4.831 . p<.001$ (see Figure 6).

\section{Lifetime trauma by exposure to study abroad trauma}

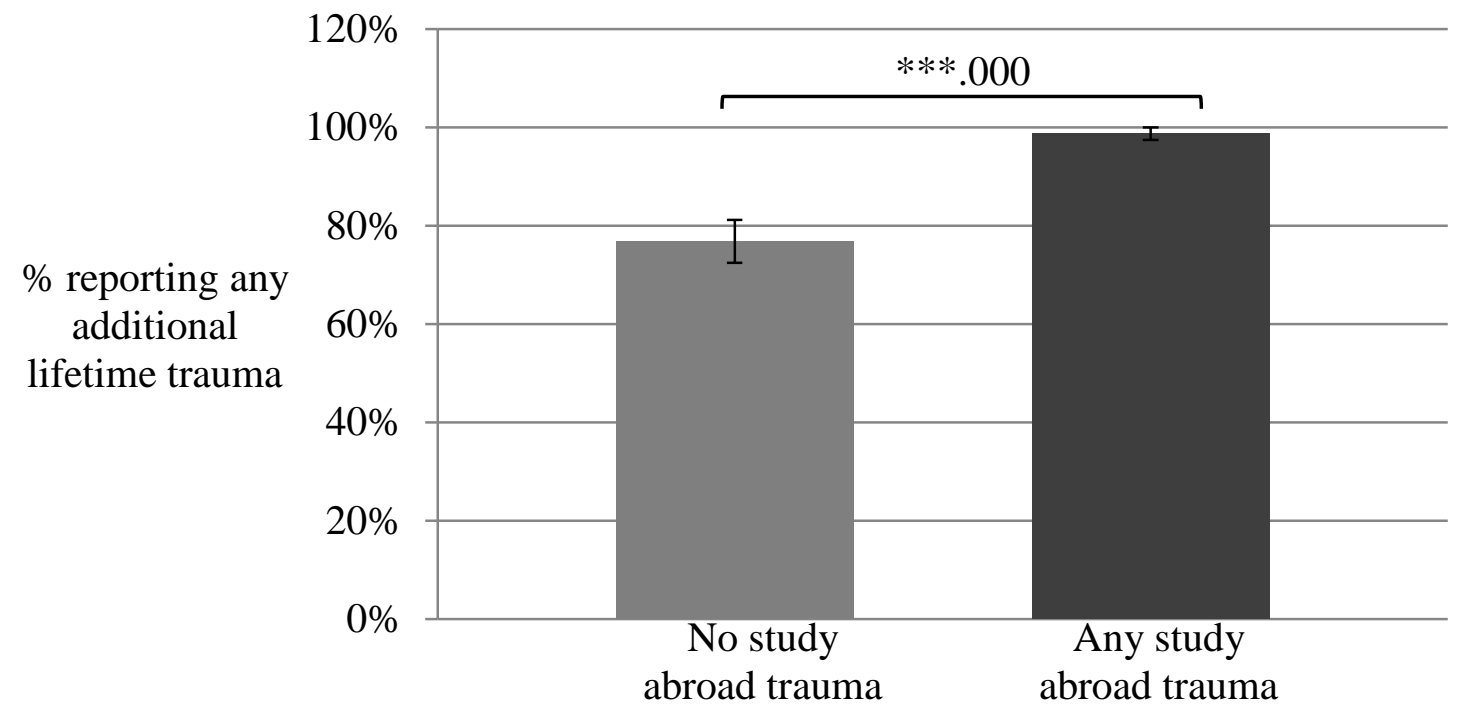

Study abroad trauma exposure

Figure 6. Trauma Symptoms by Timing of Trauma

Bar graph showing mean percent of participants reporting lifetime trauma (outside study abroad) by timing of trauma experience (lifetime trauma only and combined lifetime and study abroad).

In order to understand the relative effects of lifetime trauma and trauma experienced during study abroad, two models were tested. The first, a univariate GLM analysis determined that traumatic experiences outside of study abroad significantly 
predicted trauma outcomes, as indicated by TSC-40 scores, $F(1,172)=10.20, p=.002$, $\eta^{2}{ }_{G}=.06$. In the second model, when lifetime trauma history (outside of study abroad) was controlled for, additional trauma experienced while studying abroad was predictive of more severe posttraumatic symptoms (TSC scores) above and beyond the effects of non-study-abroad trauma experiences, $F(1,171)=45.03, p=.03, \eta^{2}{ }_{G}=.03$.

These analyses were also conducted with the World Assumptions Questionnaire (WAQ) as a dependent variable. Non-study-abroad traumatic experience did not significantly predict WAQ scores, $F(1,169)=.174, p=.678, \eta^{2}{ }_{G}=.001$. Study abroad trauma did not predict WAQ scores when controlling for additional traumatic exposure, $F(1,169)=.377, p=.54, \eta_{G}^{2}=.002$.

Of the students who reported any form of traumatic experience while studying abroad, more than a third $(35.44 \%, n=28)$ also reported experiencing at least one form of institutional betrayal. Respondents most frequently indicated an institution had created an environment where the traumatic event seemed more likely to occur (50\%) and where proactive steps had not been taken to prevent this type of experience (10.7\%). All but one type of institutional betrayal (12 total) was endorsed by at least one participant (see Table 1). 
Creating an environment in which this experience seemed more likely to occur.

Not taking proactive steps to prevent this type of experience.

Responding inadequately to the experience, if reported.

Suggesting your experience/s might affect the reputation of the institution.

Creating an environment where it was difficult for you to continue your time abroad.

Creating an environment where you no longer felt like a valued member of the institution.

Creating an environment in which this type of experience seemed common or normal.

Indicating your lack of local cultural knowledge led to the experience.

Covering up the experience.

Making it difficult to report the experience.

Mishandling your case, if disciplinary action was requested.

Providing inadequate training and education about how to avoid the experience.

Table 1. Types of Institutional Betrayal by Frequency of Experience

To evaluate the unique effects of institutional betrayal trauma, lifetime trauma was entered as a covariate within a univariate GLM. This was done because the majority of respondents who indicated experiencing study abroad trauma also reported 
additional trauma experience, which accounted for some of the variance in TSC scores. Across all trauma types, institutional betrayal did predict some of the difference in trauma outcomes between individuals who reported institutional betrayal ( $n=37, M=$ $19.81, S D=14.33)$ and those who did not report institutional betrayal ( $n=69, M=$ $15.39, S D=12.95)$. A GLM analysis controlling for lifetime traumatic experience and traumatic experience during study abroad determined that institutional betrayal accounted for some of the variance in TSC scores, $F(1,76)=2.42, p=.123, \eta^{2}{ }_{G}=.023$. When analyzing the sub-types of study-abroad traumatic events, in five of the six models controlling for non-study-abroad trauma, institutional betrayal was found to account for some of the variance in posttraumatic symptoms (see Table 2).

\begin{tabular}{|c|c|c|c|c|}
\hline $\begin{array}{l}\text { Study abroad trauma } \\
\text { type }\end{array}$ & $d f$ & $F$ & $p$ & $\eta_{G}^{2}$ \\
\hline Non-Interpersonal & 9 & .12 & .74 & $.015^{*}$ \\
\hline $\begin{array}{l}\text { Non-Interpersonal, } \\
\text { Witness }\end{array}$ & 26 & 3.91 & .06 & $.137^{* *}$ \\
\hline Interpersonal & 53 & 1.95 & .17 & $.036^{*}$ \\
\hline $\begin{array}{l}\text { Interpersonal, } \\
\text { Witness }\end{array}$ & 37 & 3.62 & .07 & $.092^{*}$ \\
\hline Existential & 9 & .01 & .93 & .000 \\
\hline Existential, Witness & 18 & 2.07 & .17 & $.111^{*}$ \\
\hline
\end{tabular}

Table 2. Institutional Betrayal as a Predictor of Study Abroad Trauma Distress Results of GLM Analysis of Trauma Symptoms Checklist - 40 by Institutional Betrayal for six types of study-abroad trauma.

$*=$ small effect $* *$ = medium effect 
To test the potential interaction between childhood (under 18) high-betrayal trauma and institutional betrayal as a predictor of trauma symptoms (TSC-40), a univariate GLM analysis was evaluated. The interaction was not found to be significant, $F(1,77)=1.25, p=.266, \eta^{2}{ }_{G}=.012$. 


\section{Discussion}

Consistent with previous examinations of trauma experienced while studying or traveling abroad (Flack et al., 2014; Kimble, Flack, \& Burbridge, 2013; Peace Corps, 2014), high rates of undergraduate students in the present study were exposed to potentially traumatic experiences while studying abroad. Existing studies can be used to approximate the traumatic exposure rate for college students. In one study, while twothirds of the college-aged sample had experienced one or more traumatic events during their lifetime, the majority of traumatic experiences (67\%) occurred before age eighteen (Vrana \& Lauterbach, 1994). That is to say, the rate of exposure to a traumatic event after age 18 (which would likely occur during college for most participants) was 22\% for students studying a their home campus in the U.S. The present study's trauma exposure rate (45.44\%) during study abroad suggests students are experiencing traumatic events at higher rates during study abroad than they would had they remained on their home campus.

These findings are a step toward addressing the dearth of existing literature on study abroad trauma, and the experience of study-abroad more generally. Researchers have informally documented the lack of consistency in evaluating students' experiences within study abroad institutions (McLeod \& Wainwright, 2009). There is no formal nation-wide standard for evaluating study abroad programs. Indeed, the 2011 Handbook for Campus Safety and Security Reporting addendum to the 2008 Clery Act ${ }^{12}$ largely absolves U.S. colleges and universities from reporting student-involved crime that

\footnotetext{
${ }^{12}$ The Clery Act is a federal statute that requires federally funded colleges and universities in the U.S. to disclose crimes that occur on or near their campuses.
} 
occurs abroad. United States colleges or universities “don’t have to disclose statistics for crimes that occur in [facilities the U.S. institution does not own or control]," in the study abroad context. The document specifies some situations where reporting would be appropriate, but specifically mentions that reporting requirements usually do not apply to host family situations. In light of the increase in numbers of students studying abroad during higher education, and the growing "gap-year” movement of high school graduates spending a year abroad before college, there is an imperative to increase the amount of public literature about these types of international experiences.

The present study’s findings on perpetration of interpersonal events are most consistent with Kimble et al.’s (2013) study of sexual assault during study abroad, which found that perpetrators were most frequently host country members. Perpetrator identity may differ based on type of traumatic event (e.g., sexual assault compared with physical assault), but the present study’s sample size precluded this level of analysis. Future research should evaluate perpetrator identities to better inform study abroad programs and students about the source of potential threats.

It is difficult to generalize beyond the present study’s demographic information about regional differences in students' experience of traumatic events because of the small sample size and unequal representation across regions. For example, it may be alarming to observe that the 14 people who experienced a traumatic event while studying abroad on the African continent experienced 47 total traumas. However, 36\% of the traumatic experiences endorsed were “other unwanted sexual experiences”, including harassment or catcalling. Such a regional analysis might be helpful in providing specific trainings based on students destination, but the present study should 
not be used as such a tool. Rather, this exploratory analysis begs further research into whether students face different risks based on region of travel.

The high prevalence of lifetime trauma experienced by all members of the sample (86.8\%) was surprising. Research into lifetime trauma exposure in college-aged individuals suggests rates from 66\% (Read, Ouimette, White, Colder, \& Farrow, 2011) to $84 \%$ (Vrana \& Lauterbach, 1994). In the present sample, lifetime trauma exposure (outside of study abroad) was even more prevalent for the group who had experienced study-abroad trauma (98.7\% had non-study-abroad trauma history). Messman-Moore and Brown’s (2006) examination of revictimization and risk-taking may partially explain this finding. Their study suggests that the delayed ability to detect risky situations that comes from experiencing previous traumas may contribute to individuals with trauma history seeking out or being more comfortable with a potentially risky experience like studying abroad.

Those involved in administrating study abroad programs at all levels should be aware of the likelihood their students have experienced a traumatic event earlier in life. This has implications at various levels of study abroad programming. First, administrators should prioritize preventing students' exposure to traumatic experiences. This is of particular importance for individuals with a history of exposure to traumatic events, for whom additional trauma would constitute revictimization. Second, it is important to design programs (including classes and outings) to be trauma-informed. Finally, those charged with responding to students who experience trauma while studying abroad should be aware of and prepared to accommodate the unique experience of someone who has been revictimized. 
Child sexual assault literature suggests that individuals who are revictimized exhibit more severe posttraumatic symptoms, greater self-blame, and are more likely to engage in maladaptive or high-risk coping mechanisms (Filipas \& Ullman, 2006). For example, a large portion (14.4\%) of participants in this study reported personally ingesting "so much alcohol or other substance that loss of consciousness or loss of control over actions resulted;” still more students (23.6\%) reported witnessing another person ingest alcohol to that extent. This may reflect the general prevalence of binge drinking in college students—but may also be indicative of particular students' attempts at coping with adverse life experiences.

In comparing students' experience of traumatic events outside of and during study abroad as a predictor of posttraumatic symptoms, the group that had experienced traumatic events in both domains displayed the highest TSC scores. This group also had experienced significantly more instances of trauma, which is consistent with research on cumulative trauma exposure. Martin, Cromer, DePrince, and Freyd (2013) examined exposure to a range of potentially traumatic events, finding that exposure to additional traumatic events exacerbated trauma symptomology, with higher betrayal traumas (e.g., emotional, physical, or sexual assault by a close other) having the strongest effect. Study abroad traumatic experiences may have some unique characteristics, but a large part of the effect of traumatic experiences during studying abroad is the accumulation of traumatic experiences. As a caveat, the present study design did not give a clear time of the occurrence of non-study-abroad trauma. Because participants considered all of the time outside study abroad, those events may be more recent trauma experienced after returning. The majority (75.6\%) of students had returned from their study abroad time 
less than one year prior, which suggests that most people had experienced a potentially traumatic event relatively recently, whether during study abroad or not.

The majority of students $(62.5 \%, n=25)$ who indicated a specific institution involved in their experience of institutional betrayal listed their school as the source of this betrayal. In some cases, this was specified as an abroad or U.S. institution, but most often, it was unspecified. Given that most students and parents view their school as a stand-in parent during the study abroad experience, this is not surprising. The list of other institutions included third-party coordinating programs, law enforcement, employers, intern site staff, and insurance companies (see Figure 7 for a complete list, with frequency of endorsement). 


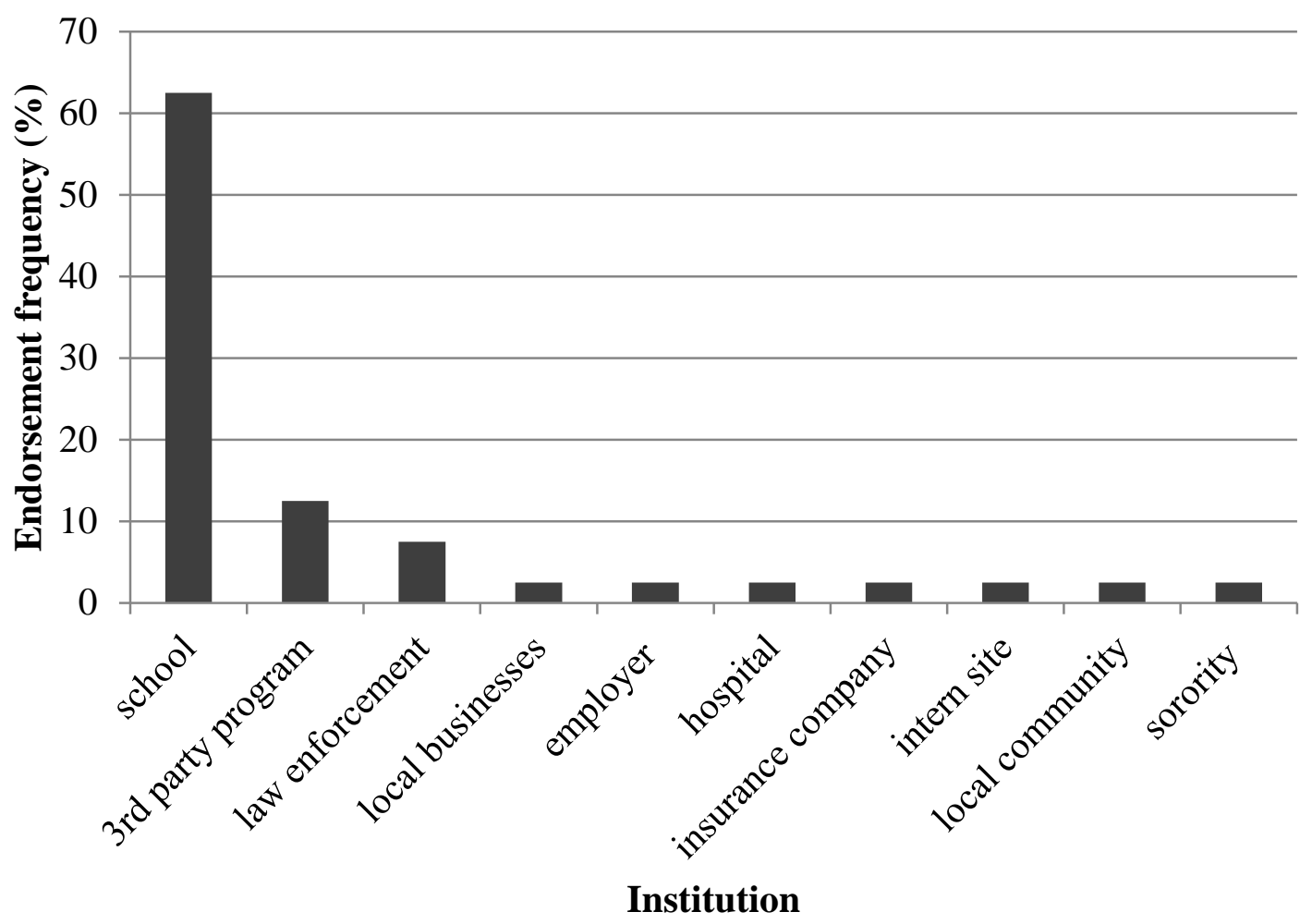

Figure 7. Types of Institutions Cited for Betrayal by Frequency of Endorsement

Bar graph depicting institutions reported as sources of institutional betrayal by students endorsing one or more institutional betrayal items related to their traumatic experience during study abroad.

The most commonly endorsed form of institutional betrayal was "creating an environment where the traumatic experience seemed more likely to occur.” In the study-abroad context, this might mean suggesting the traumatic experience was part of the local culture, so was to be expected.

The second most-frequently endorsed institutional betrayal item was "not taking proactive steps to prevent the type of experience,” which might include downplaying potential risks. It is interesting to note that the majority of institutional betrayal items endorsed were actions the institutions could have taken before the experience. As Smith \& Freyd (2013) suggest, the sense that the institution an individual trusts could have 
done something but did not protect the individual may be even more damaging than actions done afterward. What participants do not endorse also contains valuable information; no participant reported any institution "providing inadequate training or education about how to avoid the experience.” This can inform institutions’ approach. Perhaps students know the risks, but take them anyway, the experience was not something that could be avoided through training, or the training was administered but did not "stick."

Consistent with betrayal trauma theory (Freyd, 1994) and the extension of that theory to include betrayals by institutions (Smith \& Freyd, 2013), institutional betrayal did account for a portion of the variance in posttraumatic distress. Among sub-types of study-abroad trauma, institutional betrayal was more likely to predict posttraumatic distress for witnessing items. This may connect to Rausch and Knutson’s (1991) finding that participants with histories of childhood abuse were more likely to characterize their siblings' childhood experience as abusive than to characterize their own in that manner. This was true even when participants reported experiencing similar levels of physical or emotional violence directed toward both self and siblings. Rausch and Knutson linked this to the likelihood of participants attributing actions directed toward self as deserved; it was easier to identify an experience as abusive when one had witnessed it, rather than experienced it. The same may be true for members of an institution, more readily able to identify institutional betrayal perpetrated against another. Future research should examine the ability of victims to self-identify as having experienced institutional betrayal. 
As with any measure of self-reported traumatic experience, this analysis had the potential of not detecting experiences, the subject did not report-either because they did not want to report, or because they were actually "blind” to the experience having occurred (Freyd \& Birrell, 2013). In the present study, those participants who had a childhood history of high-betrayal trauma (physical, sexual, or emotional abuse by a close other) but who had not reported an institutional betrayal occurring subsequent to their experience of traumatic events during study abroad had slightly (thought not significantly) higher scores on the dissociation subscale of the TSC. This would be consistent with betrayal blindness, that these individuals honed the ability to remain unaware of abuse in response to earlier traumas, and so have more difficulty detecting traumas experienced as adults. Future research should explore the potential for previous experience of high-betrayal-trauma inhibiting detection of later institutional betrayal.

It is not clear why the World Assumptions Questionnaire was not an efficacious dependent variable. There was very little variance across WAQ scores in the sample ( $M$ $=2.49, S D=.279)$. This may suggest that the experiences students are reporting did not significantly alter their views of the overarching worldview the WAQ measures. Traumatic experiences and institutional betrayal do affect students, but perhaps not to the extent that students are generalizing about the fundamental trustworthiness of others or controllability of events. Revictimization literature further supports this explanation (Messman-Moore \& Brown, 2006). Participants who perceive themselves as partially responsible for experiencing the trauma may attribute the aftereffects to the self, rather than others or the external world. Similar attitudes were reflected in the overall positivity of students' attitude toward their study-abroad experience; the majority of 
students (97.2\%) indicated that they would recommend their study-abroad program to a friend. It's also possible that traumas experienced while abroad don’t directly affect students’ worldviews because the study-abroad setting is perceived as nonrepresentative of their day-to-day environment and experience.

\section{Limitations}

The recruitment methods necessary to access the niche population of students who have studied abroad presented some challenges. In addition to the typical issues of self-selection bias for internet self-report surveys, this study faced issues specific to institutional betrayal. Because the Study Abroad Office sent the recruitment message directly to potential participants, it is possible that students who had experienced institutional betrayal experience were less likely to engage with an institution that betrayed them. Thus, our sample may be lacking in subjects who feel most betrayed by institutions. Conversely, there may have been students with particularly negative experiences who are eager for an opportunity to hold institutions accountable and to improve the experience of future study-abroad participants. Future studies should aim to recruit a more representative sample, perhaps integrating the survey with some stage of students’ re-integration after returning from study abroad.

The limitation of our population to students from a single university may result in overrepresentation of a particular experience shared by students at that university. This could bias outcomes in two manners: (1) the university could have exemplary institutional prevention and response procedures, thus making observation of institutional betrayal unlikely; or (2) the university could have poor institutional practices that lead to disproportionately high observations of institutional betrayal that 
may not be present at other colleges or universities. The fact that the university is not the only institution contributing to the potential for institutional betrayal curtails the possibility of biases. Intermediary study abroad programs, host-country programs, colleges, and universities, housing personnel, internship directors, and other facets of the institutional framework all have the potential to contribute to institutional betrayal. This decreases the likelihood that the observations presented in this analysis represent a biased trend. 


\section{Conclusion}

While studying abroad offers students an invaluable opportunity to learn and grow in a new environment, this study suggests that while abroad, students are also likely to face significant challenges, including potentially traumatic events. Institutional betrayal may be one meaningful addition to understanding student's study abroad experiences, and the implications of those experiences for students' mental health and well being. Given the risk for trauma exposure while abroad, as well as less distressing challenges like navigating language, culture, and novel experiences, it is unrealistic to expect that every student have a fully positive “experience of a lifetime.” Yet, because institutions play such a central role in students' time abroad, it is vital that they promote students’ health and safety while supporting rich and dynamic study abroad experiences. 


\section{Bibliography}

Beck, J., Elzevier, H., Pelger, R., Putter, H., \& Voorham-van der Zalm, P. (2009). Multiple pelvic floor complaints are correlated with sexual abuse history. Journal of Sexual Medicine, 6, 193-198. doi:10.1111/j.17436109.2008.01045.x

Birrell, P.J. \& Freyd, J.J. (2006). Betrayal trauma: Relational models of harm and healing. Journal of Trauma Practice, 5(1), 49-63.

Bishop, S. C. (2013). The Rhetoric of Study Abroad: Perpetuating Expectations and Results Through Technological Enframing. Journal of Studies in International Education, 17, 4, 398-413.

Bolen, M. (2001). Consumerism and U.S. Study Abroad. Journal of Studies in International Education, 5, 3, 182-200.

Bowles, J.H., Tsantir, S., \& Powers, M. (2011). Jeanne Clery Disclosure of Campus Security Policy and Campus Crime Statistics Act: Applicability to Education Abroad Programs. Retrieved from: http://www.nafsa.org/uploadedFiles/ NAFSA_Home/Resource_Library_Assets/Networks/AREA1/jeanne_clery_discl osure.pdf

Briere, J., \& Spinazzola, J. (2005). Phenomenology and psychological assessment of complex post-traumatic states. Journal of Traumatic Stress, 18, 401-412. doi:10.1002/jts.20048

Centers for Disease Control and Prevention (2014). CDC Health Information for International Travel 2014: The Yellow Book. Ed. Gary W. Brunette, MD MPH. USA: Oxford UP, 2013.

Cohen, J. (1988). Statistical power analysis for the behavioral sciences (2nd ed.). New York: Academic Press

Courtois, C. A. (1997). Healing the incest wound: A treatment with attention to recovered-memory issues. American Journal of Psychotherapy, 51, 464- 496

DePrince \& Freyd 2001

Elliot, D. M. \& Briere, J. (1992). Sexual abuse trauma among professional women: Validating the Trauma Symptom Checklist - 40 (TSC-40). Child Abuse \& Neglect, 16, 391-398.

Engle, L., \& Engle, J. (2003). Study abroad levels: Toward a classification of program types. Frontiers: The interdisciplinary journal of study abroad, 9(1), 1-20. 
Filipas, H. H., \& Ullman, S. E. (2006). Child sexual abuse, coping responses, selfblame, posttraumatic stress disorder, and adult sexual revictimization. Journal of Interpersonal Violence, 21(5), 652-672.

Flack, W. F., Kimble, M. O., Campbell, B. E., Hopper, A. B., Petercă, O., \& Heller, E. J. (2014). Sexual Assault Victimization Among Female Undergraduates During Study Abroad A Single Campus Survey Study. Journal of interpersonal violence, 0886260514563833.

Freyd, J. J. (1994). Betrayal trauma: Traumatic amnesia as an adaptive response to childhood abuse. Ethics \& Behavior, 4, 307-329.

Freyd, J. J. (1996). Betrayal trauma: The logic of forgetting childhood abuse. Cambridge, MA: Harvard University Press.

Freyd, J. J. (1997). Violations of power, adaptive blindness, and betrayal trauma theory. Feminism and Psychology, 7, 22-32.

Freyd, J. J., DePrince, A. P., \& Gleaves, D. (2007). The State of Betrayal Trauma Theory: Reply to McNally (2007) -Conceptual Issues and Future Directions. Memory, 15, 295-311.

Freyd, J. J., DePrince, A. P., \& Zurbriggen, E. L. (2001). Self-reported memory for abuse depends upon victim-perpetrator relationship. Journal of Trauma \& Dissociation, 2(3), 5-15.

Freyd, J., \& Birrell, P. (2013). Blind to betrayal: Why we fool ourselves we aren't being fooled. (1st ed.). Hoboken, NJ: Wiley.

Gobin, R. L., \& Freyd, J. J. (2009). Betrayal and revictimization: Preliminary findings. Psychological Trauma: Theory, Research, Practice, and Policy, 1(3), 242.

Goldberg, LR. \& Freyd, J.J. (2006). Self-reports of potentially traumatic experiences in an adult community sample: Gender differences and test-retest stabilities of the items in a Brief Betrayal-Trauma Survey. Journal of Trauma \& Dissociation, 7(3), 39-63.

Hartjes, L. B., Baumann, L. C., \& Henriques, J. B. (2009). Travel health risk perceptions and prevention behaviors of US study abroad students. Journal of travel medicine, 16(5), 338-343.

Institute of International Education (2013). Open Doors: Report on International Educational Exchange. Washington DC: November, 2013. Retrieved from http://www.iie.org/Who-We-Are/News-and-Events/Press-Center/PressReleases/2013/2013-11-11-Open-Doors-Data\#.UpEWhGTwLrs 
Janoff-Bulman, R. (1992). Shattered assumptions: Towards a new psychology of trauma. New York, NY: The Free Press.

Kaehler, L. A., \& Freyd, J. J. (2009). Borderline personality characteristics: A betrayal trauma approach. Psychological Trauma: Theory, Research, Practice, and Policy, 1, 261-268. doi:10.1037/a0017833

Kaler, M. E. (2009). The world assumptions questionnaire: Development of a measure of the assumptive world. (Unpublished doctoral dissertation). Retrieved from http://conservancy.umn.edu/bitstream/11299/55049/1/Kaler_umn_0130E_10613 .pdf

Kelley, L.P, Weathers, F.W., Mason, E.A., \& Pruneau, G.M. (2012) Association of Life Threat and Betrayal With Posttraumatic Stress Disorder Symptom Severity. Journal of Traumatic Stress, 25, 408-415.

Kimble, M., Burbridge, E., \& Flack, J. W. F. (2013). Study abroad increases risk for sexual assault in female undergraduates: A preliminary report. Psychological Trauma: Theory, Research, Practice, and Policy, 5, 5, 426-430.

Koss, M. P., \& Oros, C. J. (1982). Sexual Experiences Survey: A research instrument investigating sexual aggression and victimization. Journal of Clinical and Consulting Psychology, 50, 455-457.

Martin, C. G., Cromer, L. D., DePrince, A. P., \& Freyd, J. J. (2013). The role of cumulative trauma, betrayal, and appraisals in understanding trauma symptomatology. Psychological Trauma: Theory, Research, Practice, and Policy, 5(2), 110.

McLeod, M., \& Wainwright, P. (2009). Researching the study abroad experience. Journal of Studies in International Education, 13(1), 66-71.

Messman- Moore, T. L., \& Brown, A. L. (2006). Risk perception, rape, and sexual revictimization: A prospective study of college women. Psychology of Women Quarterly, 30(2), 159-172.

Mayseless, O., \& Popper, M. (2007). Reliance on leaders and social institutions: An attachment perspective. Attachment \& human development, 9(1), 73-93.

Olejnik, S., \& Algina, J. (2003). Generalized eta and omega squared statistics: measures of effect size for some common research designs. Psychological methods, 8(4), 434.

Peace Corps (2014). Statistical Report of Crimes Against [Peace Corps] Volunteers 2013 http://files.peace corps.gov/multimedia/pdf/policies/volsafety2013.pdf 
Rausch, K., \& Knutson, J. F. (1991). The self-report of personal punitive childhood experiences and those of siblings. Child abuse \& neglect, 15(1), 29-36.

Read, J. P., Ouimette, P., White, J., Colder, C., \& Farrow, S. (2011). Rates of DSMIV-TR trauma exposure and posttraumatic stress disorder among newly matriculated college students. Psychological Trauma: Theory, Research, Practice, and Policy, 3(2), 148.

Redden, E. (2014, February 13). A Rape Response Gone Wrong. Inside Higher Ed.

Ross, C. (2005). Long term effects of child sexual abuse: Childhood sexual abuse and psychosomatic symptoms in irritable bowel syndrome. Journal of Child Sexual Abuse: Research, Treatment, \& Program Innovations for Victims, Survivors, \& Offenders, 14, 27-38. doi:10.1300/J070v14n01_02

Smith, C. P., \& Freyd, J. J. (2013). Dangerous safe havens: institutional betrayal exacerbates sexual trauma. Journal of Traumatic Stress, 26, 1, 119-24.

Smyth, C. (2014, January 11). A Violation of Women's Rights in Monteverde [Web log]. Retrieved from https://thetransientbiologist.wordpress.com/2014/01/11/aviolation-of-womens-rights/\#more-822

Trippany, R., Helm, H., \& Simpson, L. (2006). Trauma reenactment: Rethinking borderline personality disorder when diagnosing sexual abuse survivors. Journal of Mental Health Counseling, 28, 95-110.

University of Oregon Office of the Registrar. (2013). Facts at a Glance. Retrieved from http://registrar.uoregon.edu/sites/default/files/statistics/Facts-at-a-Glance-Fall2013.pdf.

Vrana, S., \& Lauterbach, D. (1994). Prevalence of traumatic events and post- traumatic psychological symptoms in a nonclinical sample of college students. Journal of traumatic stress, 7(2), 289-302.

Weathers, F.W., Blake, D.D., Schnurr, P.P., Kaloupek, D.G., Marx, B.P., \& Keane, T.M. (2013). The Life Events Checklist for DSM-5 (LEC-5). Instrument available from the National Center for PTSD at www.ptsd.va.gov. 


\section{Appendix A: Recruitment Letter}

Subject Line: Participate in Survey about Study Abroad Experience (Win \$25!)

Good morning,

The Office of International Affairs invites you to participate in a research study being conducted by a UO undergraduate student. There is more information about the study in this message from the researcher:

My name is Naomi Wright and I am completing my undergrad thesis in the Psychology Department at the University of Oregon. I am writing to invite you to participate in my research study about students' experiences while studying abroad. You are eligible to participate because you studied or interned outside the U.S. during your time at the UO.

If you decide to participate in this study, you will take an online survey, requiring no more than 30 minutes to complete. If you complete the questionnaire, you will be entered in a drawing to receive a $\mathbf{\$ 2 5 . 0 0}$ gift certificate to Amazon.com.

Participation is completely voluntary. You can choose to be in the study or not. This research is about Study Abroad, but it is being conducted independent of the Office of International Affairs and UO Study Abroad Programs. None of the information you provide will be seen by anyone other than the psychology researchers working directly on this study.

If you'd like to participate, please click this link: https://oregon.qualtrics.com/SE/?SID=SV bfiFltWxyyiqpYF. All questions about the study can be directed to me via email, naomiw@uoregon.edu.

Thank you very much.

Sincerely, Naomi Wright 


\section{Appendix B: Secondary Recruitment Message}

Thank you for your participation. We would like to understand the experiences of as many UO students who have studied abroad as possible. If you know of any UO students who might be interested in taking this survey, please feel free to share the link to it: [LINK]

Sincerely,

Naomi Wright, Undergraduate, Clark Honors College

Carly Smith, $M A, M S$

Jennifer Freyd, PhD 


\section{Appendix C: Consent Script}

You are being asked to participate in a research study looking at the experiences of students who have studied abroad. You are eligible to participate in this study because you have studied abroad during your time at the University of Oregon. Studying abroad means any international participation for which you received collegelevel credit, including direct enrollment in an international university, field-based studying with a group from the US, professional internships, or a combination of these programs. There is no minimum credit or time requirement, though you will be asked to provide information about the duration and credits received during the survey.

We ask that you read this form and ensure you understand what this study involves before agreeing to be in the study.

The purpose of this study is to investigate how students are affected by the institutions that support them while they study or intern abroad. All participants in this study attend the University of Oregon and have studied or interned abroad during their time at the university.

If you agree to be in this study, we would ask you to take an online survey that will take approximately 30 minutes to complete and must be completed in one session. The questionnaire will include some basic questions about you (age, gender identity, ethnicity, etc.); questions about stressful events you may have experienced in your life or while studying abroad; questions about any institutions that may have played a role in those events; questions about your mental well-being; and questions about your attitudes and views of the world. You will use the mouse and keyboard to indicate your responses to questions as indicated. There are six sections in the questionnaire. Each will take approximately five minutes to complete.

Some people may find parts of the questionnaire uncomfortable, such as, "If this event has happened to you, please indicate your best estimate of how many times you were deliberately attacked that severely by someone with whom you were very close. When responding to items in this survey, you may leave any individual items blank that you do not wish to answer. This will not affect your credit. We anticipate the information collected will help shape the experience of students studying abroad in the future. While there may not be a direct benefit to you, we anticipate the information collected in this study will help shape the experience of students studying abroad in the future.

If you complete the survey you will have the option of entering a drawing to win a \$25.00 gift certificate to the online retailer Amazon.com. To enter the drawing, click the link at the end of the survey that says "Enter Drawing." You will be presented with a page where you can enter your first and last name and a @uoregon.edu email address. We ask for@uoregon.edu addresses to ensure you are a University of Oregon student. This contact information will not be connected in any way to your responses in the earlier questionnaire. Discontinuing the survey after the consent page will not result in any penalty, but you will not be eligible to receive a gift certificate.

The records of this study will be kept private. In any sort of report we may publish, we will not include any information that will make it possible to identify a participant. All electronic information will be coded and secured using a password- 


\section{Appendix C: Consent Script, cont.}

protected file. Access to the records will be limited to the researchers involved with this study. No information you provide in this survey will be linked to your identity in any way. The raw data, with no identifying information, will be housed on a server that University Administrators will be able to access. To ensure your confidentiality, you will receive an email with instructions for receiving credit for your participation upon completion of the survey.

Your participation is voluntary. Your decision whether or not to participate will not affect your relationship with the UO Psychology Department, the UO Linguistics Department, or the UO Study Abroad Office. If you decide to participate, you are free to withdraw your consent and discontinue participating at any time without penalty.

For questions about this research question, contact Naomi Wright at naomiw@uoregon.edu or her advisor, Jennifer Freyd at jjf@uoregon.edu. If you have any questions concerning your rights as a research participant, please contact Research Compliance Services, University of Oregon, Eugene, OR 97403, 541-346-2510, or email hscoord@uoregon.edu .

You may print or save this consent form if you would like to keep a copy of the information.

Please choose 'Agree' if you have read and understood the description of the study above, and wish to participate. If you do not wish to participate, please choose "Do Not Agree." 


\section{Background:}

\section{Appendix D: Debriefing Statement}

We are interested in how the support provided by organizations such as colleges, universities, or third-party study-abroad programs affects people when they experience a stressful or traumatic event. We know that students studying abroad may be exposed to traumatic events, but very little is known about the role of institutions in supporting students in these situations.

\section{Purpose:}

This study's specific aim was to investigate students' experience of stressful or traumatic events while studying abroad, how these experiences affected them psychologically, and how the students feel about the institutions (college, study abroad program, host family) that supported them during this experience.

\section{Your part:}

The part you play in this research is important! This study is about the real experiences of college students, so you are exactly who this study is about. By participating, you are helping us to better understand the risks faced by students like you who are studying abroad, and how to provide the optimal support for these students in stressful situations.

\section{Feedback and further information:}

If you have additional questions about this study, please feel free to email Naomi Wright at naomiw@uoregon.edu or her advisor, Jennifer Freyd at jjf@uoregon.edu. If you have any questions concerning your rights as a research participant, please contact the Office for the Protection of Human Subjects, University of Oregon, Eugene, OR 97403, 541-346-2510, or email hscoord@uoregon.edu .

If, after participating in this survey, you feel you want to talk to someone about any personal experiences that may have come up, these services can provide confidential support: University of Oregon Counseling Center (541-346-3227), Center for Community Counseling (541-344-0620), or Whitebird Clinic 24 Hour Crisis Line (541-687-4000).

You may print or save this debriefing form if you would like to keep a copy of the information. Thank you very much for participating! 


\section{Appendix E: BBTS}

\section{Brief Betrayal Trauma Survey}

For each of the following events, please indicate your best estimate of how many times the event has happened to you. ${ }^{13}$

1. You were in a major earthquake, fire, flood, hurricane, or tornado that resulted in significant loss of personal property, serious injury to yourself or a significant other, the death of a significant other, or the fear of your own death.

2. You were in a major automobile, boat, motorcycle, plane, train, or industrial accident that resulted in similar consequences.

3. You were deliberately attacked so severely as to result in marks, bruises, burns, blood, or broken bones by someone with whom you were very close.

4. You were deliberately attacked that severely by someone with whom you were not close.

5. You were made to have some form of sexual contact, such as touching or penetration, by someone with whom you were very close (such as a parent or lover).

6. You were made to have such sexual contact by someone with whom you were not close.

7. You were emotionally or psychologically mistreated over a significant period of time by someone with whom you were very close (such as a parent or lover).

8. You were emotionally or psychologically mistreated over a significant period of time by someone with whom you were not close.

9. You experienced the death of one of your own children.

10. You experienced a seriously traumatic event not already covered in any of these questions.

13 For each question, participants are asked to indicate whether the event happened "never," "1 or 2 times," or, "more than that," during three age categories: before age 18, after age 18 not while studying abroad, and after age 18 while studying abroad. 


\section{Appendix F: LEC-5}

\section{Life Events Checklist DSM-5 for Outside Of and During Study Abroad}

For this section we'll ask about a number of difficult or stressful things that sometimes happen to people. For each event check one or more boxes to the right that indicate: (a) it happened to you personally; (b) you witnessed it happen to someone else; (c) you learned about it happening to a close family member or close friend; (d) you were exposed to it as part of your job (for example, paramedic, police, military, or other first responder; or (e) you're not sure if it fits. If you have never experienced, witnessed, or learned about the event, leave the boxes to the right blank.

For this section, please consider your entire life outside of your study abroad experience (growing up, attending university, and after returning from studying abroad, if applicable). ${ }^{14}$

1. Natural disaster (for example, flood, hurricane, tornado, earthquake)

2. Fire or explosion

3. Transportation accident (for example, car accident, boat accident, train wreck, plane crash)

4. Serious accident at work or school, home, or during recreational activity

5. Ingestion of so much alcohol or other substance that loss of consciousness or loss of control over actions resulted

6. Physical assault (for example, being attacked, hit, slapped, kicked, beaten up)

7. Assault with a weapon (for example, being shot, stabbed, threatened with a knife, gun, bomb)

8. Sexual assault (rape, attempted rape, made to perform any type of sexual act through force or threat of harm)

9. Other unwanted or uncomfortable sexual experience (including harassment or catcalling)

10. Combat or exposure to a war-zone (in the military or as a civilian)

11. Captivity (for example, anything from being locked in a room or building to being kidnapped or abducted)

12. Life-threatening illness or injury

13. Severe human suffering

14. Sudden, violent death (for example, homicide, suicide)

15. Sudden, unexpected death of someone close to you

16. Serious injury, harm, or death you caused to someone else

17. Any other very stressful event or experience

If you responded to 17. "Any other very stressful event or experience” please briefly

describe that event or experience here:

14 Participants will be shown this questionnaire twice, directed to focus first on all times outside of studying abroad, second on solely the time spent studying abroad. Thus, the second presentation will indicate, "For the next section, please consider only the time during your study abroad experience." 


\section{Appendix F: LEC-5, cont.}

Selective item presentation: only for the during study abroad version of the LEC-5, if a participant endorses any of the above items with an interpersonal component, they will be presented with the following item:

You indicated you experienced an event or events involving interpersonal violence. Who was the person involved in perpetrating the violence?
a. A U.S. American you knew.
b. A U.S. American you did not know.
c. A host-country member you knew.
d. A host-country member you did not know. 


\section{Appendix G: IBQ-IS}

Institutional Betrayal Questionnaire - International Experiences

This section will ask you to think about larger institutions to which you belong or have belonged to during your study abroad experience, which may or may not call to mind specific individuals. This may include large systems such as a university (in the U.S. or abroad), a study abroad program, an internship organization, a government, a law enforcement agency, or organized religion. Additionally, this can refer to parts of these systems such as a university department or office, a host family, or an internship team.

In the previous section you indicated difficult or stressful thing(s) you were exposed to while studying abroad. Please think back on the event(s) or experience(s) when responding to the following questions.

Did an institution play a role in the event or experience by (check all that apply)...

1. Not taking proactive steps to prevent this type of experience/s?

2. Providing inadequate training and education about how to avoid the experience?

3. Creating an environment in which this type of experience/s seemed common or normal?

4. Creating an environment in which this experience seemed more likely to occur (e.g. "That was just a cultural experience")?

5. Making it difficult to report the experience/s?

6. Responding inadequately to the experience/s, if reported?

7. Mishandling your case, if disciplinary action was requested?

8. Covering up the experience/s?

9. Denying your experience/s in some way?

10. Indicating your lack of local cultural or language knowledge led to the experience?

11. Punishing you in some way for reporting the experience/s (e.g., loss of credit or proposing you discontinue study abroad)?

12. Suggesting your experience/s might affect the reputation of the institution (e.g., asking you not to post about the experiences on a blog)?

13. Creating an environment where you no longer felt like a valued member of the institution?

14. Creating an environment where it was difficult for you to continue your time abroad?

Would you recommend that a friend participate in the same study abroad program? Yes/No

Did the stressful experience(s) you indicated contribute to your answer to the previous question?

Yes/No 


\section{Appendix G: IBQ-IS, cont.}

Would you like to visit your study abroad country or region again?

Yes/No

Did the stressful experience(s) you indicated contribute to your answer to the previous question?

Yes/No

During your time spent studying abroad, how isolated from other people from your home country did you feel?

Not at all

Very little

Somewhat

To a great extent

During your time spent studying abroad, how dependent on institutions (U.S. or abroad college or university, study abroad or internship program, etc.) did you feel?

Not at all

Very little

Somewhat

To a great extent

Please briefly identify the institution(s) involved (e.g., school, church): 


\section{Appendix H: TSC-40}

\section{Trauma Symptoms Checklist - 40}

How often have you experienced each of the following in the last month? (For each item, indicate "never," “occasionally," "fairly often," “often,” or "very often.”

1. Insomnia (trouble getting to sleep)

2. Restless sleep

3. Nightmares

4. Waking up early in the morning \& can't get back to sleep

5. Not feeling rested in the morning

6. Waking up in the middle of the night

7. Weight loss (without dieting)

8. Feeling isolated from others

9. Loneliness

10. Low Sex Drive

11. Sadness

12. "Flashbacks" (sudden, vivid, distracting memories)

13. "Spacing out" (going away in your mind)

14. Headaches

15. Stomach problems

16. Uncontrollable crying

17. Anxiety attacks

18. Trouble controlling temper

19. Trouble getting along with others

20. Dizziness

21. Passing out

22. Desire to physically hurt yourself

23. Desire to physically hurt others

24. Sexual problems

25. Sexual overactivity

26. Not feeling satisfied with your sex life

27. Having sex that you didn't enjoy

28. Bad thoughts or feelings during sex

29. Being confused about your sexual feelings

30. Sexual feelings when you shouldn't have them

31. Fear of men

32. Fear of women

33. Unnecessary or over-frequent washing

34. Feelings of inferiority

35. Feelings of guilt

36. Feelings that things are "unreal"

37. Memory problems

38. Feelings that you are not always in your body

39. Feeling tense all the time

40. Having trouble breathing 


\section{Appendix I: WAQ}

World Assumptions Questionnaire

In the following section, please rate the following statements on how much you agree or disagree with them using the following scale:

\begin{tabular}{|l|l|l|l|l|l|}
\hline $\begin{array}{l}1=\text { Strongly } \\
\text { Agree }\end{array}$ & $2=$ Agree & $\begin{array}{l}3=\text { Slightly } \\
\text { Agree }\end{array}$ & $\begin{array}{l}4=\text { Slightly } \\
\text { Disagree }\end{array}$ & $5=$ Disagree & $\begin{array}{l}6=\text { Strongly } \\
\text { Disagree }\end{array}$ \\
\hline
\end{tabular}

1. Most people can be trusted.

2. I don't feel in control of the events that happen to me.

3. You usually can know what is going to happen in your life.

4. It is difficult for me to take most of what people say at face value.

5. It is very difficult to know what others are thinking.

6. Anyone can experience a very bad event.

7. People often behave in unpredictable ways.

8. People are less safe than they usually realize.

9. For the most part, I believe people are good.

10. I have a great deal of control over what will happen to me in my life.

11. You never know what's going to happen tomorrow.

12. Other people are usually trustworthy.

13. People's lives are very fragile.

14. It is hard to know exactly what motivates another person.

15. Most people cannot be trusted.

16. People fool themselves into feeling safe.

17. It is hard to understand why people do what they do.

18. Most of what happens to me happens because I choose it.

19. Terrible things might happen to me.

20. It is ultimately up to me to determine how events in my life will happen.

21. It can be very difficult to predict other people's behavior.

22. What people say and what they do are often very different things. 